\title{
Archimedean Metanorms
}

\author{
J. Adam Carter ${ }^{1}[\mathbb{C}$
}

Published online: 29 August 2018

(c) The Author(s) 2018

\begin{abstract}
One notable line of argument for epistemic relativism appeals to considerations to do with non-neutrality: in certain dialectical contexts-take for instance the famous dispute between Galileo and Cardinal Bellarmine concerning geocentrism-it seems as though a lack of suitably neutral epistemic standards that either side could appeal to in order to (non-questionbeggingly) resolve their first-order dispute is itself-as Rorty (Philosophy and the mirror of nature, Princeton University Press, Princeton, 1979) influentially thought—evidence for epistemic relativism. In this essay, my aim is first to present a more charitable reformulation of this line of reasoning, one that is framed not merely in terms of the availability of epistemic norms that are suitably neutral between interlocutors, but in terms of the availability of what I call Archimedean metanorms. Once this more charitable line of argument is developed, I show how, even though it avoids problems that face 'non-neutrality' versions of the argument, it nonetheless runs into various other problems that appear ultimately intractable and, further, that the strategy in question gives us no decisive reason to draw the relativist's conclusion rather than the Pyrrhonian sceptic's.
\end{abstract}

Keywords Epistemic relativism $\cdot$ Relativism and epistemology $\cdot$ Metaepistemology $\cdot$ Disagreement

"Give me a fulcrum on which to rest, and I will move the earth." -Archimedes.

\section{Scepticism, Relativism and Disagreement}

Allegedly irresolvable disagreements have played important philosophical roles in the history of scepticism and (of most interest for our purposes) relativism. In the Pyrrhnonian tradition, 'disagreement' is one of the Five Modes of Agrippa ${ }^{1}$ - viz., one of five dialectical strategies (along with infinite regress, relativity, hypothesis, and reciprocity) intended to induce suspension of judgment. In Outlines of Pyrrhonism, Sextus Empiricus says:
The mode deriving from disagreement is that by means of which we discover that, with regard to the matter proposed, there has arisen, both in ordinary life and among philosophers, an undecidable dispute owing to which we end up in suspension of judgment, since we are not able to choose or to reject anything. (PH I $165-169)^{2}$

The injunction of suspension of judgment would in no way be motivated by the presence of disagreement if it were (epistemically) permissible to decide what was so without taking into account the presence of differing opinion. But the discovery of a differing opinion, according to the Pyrrhonian, is supposed to be-at least when the opinions in competition are suitably balanced ${ }^{3}$ - constraining on what
J. Adam Carter

adam.carter@glasgow.ac.uk

1 COGITO Epistemology Group, Philosophy, University of Glasgow, 67-69 Oakfield Avenue, Glasgow, Scotland G12 8QQ, UK

\footnotetext{
$\overline{1}$ These modes are attributed to Agrippa by Diogenes Laertius (DL IX 88).

2 Cited also in Machuca (2011).

3 The term used by Sextus is equipollent.
} 
we are in a position to permissibly decide. Consider further that it would not be constraining if both parties of the dispute could at the same time be equally right. ${ }^{4}$ Thus, as Markus Lammenranta (2008, p. 18) notes, an implicit premise in the Agrippan mode of disagreement, qua dialectical strategy aimed at suspension of judgment, is that at most one party to any such 'undecidable' ${ }^{5}$ or irresolvable dispute is right; he presents the crux of the idea as follows:

1. $\mathrm{S} 1$ believes that $\mathrm{p}$.

2. $\mathrm{S} 2$ believes that $\mathrm{p}$.

3. At most one of them is right. ${ }^{6}$

4. The disagreement between $\mathrm{S} 1$ and $\mathrm{S} 2$ is irresolvable.

5. We should suspend judgment about $\mathrm{p}$.

While the Pyrrhonian line on the epistemic significance of irresolvable disagreement presupposes (3), the Pyrrhonian doesn't explicitly try to argue for (3). In this respect, the Pyrrhonian sceptic is much like the contemporary conciliationist in the peer disagreement literature (e.g., Elga 2007; Feldman 2007). According to the conciliationist, certain kinds of disagreements—viz., revealed peer disagreements—should lead us to withhold judgment (or at least significantly lower our credence in the target proposition). And the rationale for this quasi-sceptical conclusion also takes for granted a premise like (3).

But what if the very presence of disagreements with certain kinds of epistemic features was itself a reason to reject (3)? If this were so, then the Pyrrhonian line from disagreement to scepticism turns out to be a set of jointly inconsistent claims disguised as an argument. And with (3) omitted from the reasoning, it's hard to see how any kind of sceptical conclusion would follow from observed facts

\footnotetext{
4 The contemporary term for arguments with this feature is 'faultless disagreement'. This term, however, is typically associated with a linguistic strategy type for a form of relativism which is different from the motivation for relativism that will be the focus of this paper. For further clarification on this point, see Footnote 13.

${ }^{5}$ For discussion on this translation from Greek, see Barnes (2007, p. 19). The original Greek, according to Barnes, implies that the term for 'undecided' indicates that the argument in question 'awaits decision', and so the implication is that 'for all the sceptic knows, the disagreement might, in the future, be resolved' (2007, p. 19). In this respect, the Pyrrhonian sceptic is importantly different from the Academic sceptic, who will assert conclusively that a given disagreement will never be resolved.

${ }^{6}$ It is worth noting that the move from (1) and (2) to (3) is not one that concerns the epistemic status (e.g., justification) of the conflicting beliefs; rather, the claim reached on the basis of (1) and (2) is that at least one party must hold a false belief. This point, which rests just on the idea that conflicting beliefs can't both be true, does not imply any particular position with respect to what it is rational to do in the face of disagreement.
}

about irresolvable disputes. ${ }^{7}$ Even more, if the presence of an irresolvable dispute ${ }^{8}$ gave us reason to reject the realist/ objectivist $^{9}$ (3), it would at the same time be a boon-as some thinkers have reasoned-for relativism.

To see how this is so, just consider Richard Rorty's (1979, pp. 328-333) oft-cited example of the seventeenth century dispute between Cardinal Bellarmine and Galileo concerning the truth of the matter of whether the sun revolved around the earth, a view Bellarmine affirmed on the basis of Scripture. Relevant to this dispute, Galileo maintained, was that moons could be observed orbiting Jupiter, evidence that, contra geocentrism, not everything revolves around the earth.

The epistemic features of the situation between Galileo and Bellarmine are summarised nicely by Harvey Siegel (2004) as follows:

Not only did the two parties disagree as to the truth of the relevant claim-Galileo affirmed the existence of the moons, while his opponents denied it-they also disagreed about the relevant standards (telescopic observation? naked eye observation? Scripture? Aristotle?) to which appeal should be made in order to resolve their disagreement [...] Any proposed metastandard that favors regarding naked eye observation, Scripture, or the writings of Aristotle as the relevant standard by which to evaluate "the moons exist" will be judged by Galileo as unfairly favoring his opponents since he thinks he has good reasons to reject the epistemic authority of all these proposed standards. [L] ikewise, any proposed meta-standard that favors Galileo's preferred standard, telescopic observation, will be judged to be unfair by his opponents, who claim to have good reasons to reject that proposed standard (2004, p. 751).

In short, it looks like Galileo and Bellarmine's dispute runs very deep indeed; they disagree not only about whether

\footnotetext{
${ }_{7}$ For discussion on this point, see Carter (2016, Chaps. 3-5).

8 A point of clarification: some disagreements may not in fact be resolvable due to entirely practical concerns-e.g., a party to the dispute becomes tired, or loses her vocal chords, or both become bored or simply 'agree to disagree' to keep the peace. Each of these explanations for the practical irresolvability of a disagreement, though, seem to be irrelevant to whether we should draw any interesting philosophical conclusion.

${ }^{9}$ Note that by denying (3), one thereby parts ways with the objectivity of the truth of the proposition that is the subject of the dispute. Maintaining (3), by contrast, comports with views that have variously been described as 'realist' (Cuneo 2007), 'absolutist' (Boghossian 2006; MacFarlane 2014). For discussion, see Baghramian and Carter (2015).
} 
moons orbit Jupiter. But they also disagree about what kinds of evidence are even relevant to settling the question. Moreover, it doesn't appear that either is in a position to settle this second-order question about evidence without begging the question vis-à-vis what counts as evidence ${ }^{10}$; after all, it looks very much as though there is no meta-standard either could appeal to which would be suitably neutral in their dialectical context. And Rorty's assessment from such considerations is that we should conclude that each is justified relative to his own 'epistemic grid' or epistemic system, ${ }^{11}$ and that nothing more can be said. ${ }^{12}$

As Siegel puts it in characterising Rorty's pro-relativist diagnosis of the Bellarmine/Galileo dispute, "the absence of neutral (meta-) standards seems to make the case for relativism" (2004, p. 751). This is a remarkable piece of reasoning, ${ }^{13}$ and one that takes us a long way from where the Pyrrhonian would have been led.

\section{No Neutrality, Therefore Relativism}

In short, if relativists like Rorty are right, then the purported fact that there was no suitably neutral meta-standard available to Bellarmine and Galileo to which to appeal to rationally resolve their dispute is a fact with pro-relativist import. And more generally, what this means is that considerations about non-neutrality, in actual, concrete dialectical contexts, are relativism-relevant.

Following Siegel (2011), we may refer to this general line of reasoning on behalf of the relativist—one that has been

\footnotetext{
${ }^{10}$ See, for instance, Fogelin (1985), Campolo (2007) and Siegel (2013) for additional discussions of features that mark deep disagreements in argumentation theory.

11 Rorty (1979, p. 331) takes the term 'grid' from Foucault.

12 Put another way: there is no epistemic-grid- or epistemic-systemneutral vantage point from which to say who is right and who is wrong.

13 Note that the kind of move under consideration here is distinct from linguistically motivated 'faultless disagreement' arguments (e.g., Kölbel 2004; MacFarlane 2007). For one thing, faultless-disagreement-style arguments maintain on the basis of our patterns of using a given term that a truth-relativist semantics best accommodates that pattern of use. This is the case both when the expression given the relativist treatment by the proponent of faultless disagreement is a non-epistemic expression (e.g., 'tasty') as well as when it is an epistemic expression (e.g., 'knows'). Secondly, faultless-disagreement-style arguments are not going to regard any one particular historical dispute as conclusive evidence for the claim that the disagreement in question is faultless. Any one case would, within a faultless-disagreement-style argument, be considered inconclusive data from which to extrapolate such a conclusion. By contrast, the kind of move under discussion here maintains that single cases (such as Galileo vs. Bellarmine) are, in principle, sufficient evidence for relativism. For an overview of different sources of motivation for (different forms of) epistemic relativism, see Baghramian and Carter (2015).
}

defended recently by Hales (2014) ${ }^{14}$ —as the 'No Neutrality, Therefore Relativism' template argument strategy. The key premises of the argument-framed in terms of the Galileo/ Bellarmine debate often taken as a reference point ${ }^{15}$-are as follows:

\subsection{No Neutrality, Therefore Relativism}

6. There can be a non-relative resolution of the dispute concerning the existence of the moons, only if there is available an appropriately neutral meta-norm.

7. In the context of the dispute between Galileo and Bellarmine, no such appropriately neutral meta-norm is available.

8. Therefore, it's not the case that there can be a non-relative resolution of the dispute concerning the existence of the moons.

9. Therefore, epistemic relativism is true.

Obviously, (8) doesn't entail (9). We'd need some further 'bridge' premise ${ }^{16}$ connecting the truth of epistemic relativism with the claim that there can be no non-relative resolution of the dispute in question. We'll return to this point.

But what to make of (6) and (7)? Premise (7) maintains that, in the context of the dispute between Galileo and Bellarmine, no such appropriately neutral meta-norm is available. But what sense of 'availability' is the relevant one here? Relatedly: what, exactly, is unavailable? Moreover, as is relevant to (6), why should the capacity of interlocutors to locate such a norm in this or similar dialectical contexts matter for the purposes of assessing whether relativism is true?

Assessing the relativist's move from (irresolvable) disagreement to relativism requires that we get some grip on these questions. In what follows, I hope to make some headway on this score. The remainder of the paper will accordingly be organised around two broad questions, the elusiveness question and the relevance question.

Elusiveness question: What exactly is the thing (i.e., appropriately neutral metanorm?) that Galileo and Bellarmine are said to be unable to locate in this dialectical context? In what sense is this thing unavailable to them?

Relevance question: And why should it matter whether they could (or could not) locate such a thing,

\footnotetext{
${ }^{14}$ I've criticised the substantive details of Hales's interesting version of this template argument elsewhere (e.g., Carter 2016, Chap. 4, 2018a). Here, my focus is on the general strategy type.

15 This is due in the main to Rorty (1979) Boghossian (2006) so MacFarlane (2008)

16 See Carter (2016, Chap. 4) a detailed discussion of this strategy of argument.
} 
in the context of their dispute? Why should the matter of whether epistemic relativism is true turn on these kinds of facts? What considerations are relevant in determining this?

In what follows, I'll aim to answer these questions, though not in a way that will be congenial to the relativist. Here is the plan for what follows: first, I'll show how engaging with the elusiveness question leads us naturally to see how to frame a more promising case than relativists have offered thus far for defending a version of the 'No Neutrality, Therefore Relativism' argument, one framed not in terms of mere neutrality, but in terms of Archimedean metanorms. I'll then show-with reference to both the elusiveness question and the relevance question-how even this more promising strategy runs ultimately into dead ends, and that the underlying problems that lead to these dead ends are intractable ones. At the end of the day, the relativist's move from purportedly irresolvable disagreements to relativism is on no better ground than is the Pyrrhonian's move from such cases to the rival sceptical conclusion.

\section{The Elusiveness Question}

What exactly is the thing (i.e., appropriately neutral metanorm) that Galileo and Bellarmine are said to be unable to locate in their dialectical context? And in what sense is this thing unavailable to them? Settling these issues is needed in order to work out in a principled way whether (7) of the No Neutrality, Therefore Relativism argument is true or false. ${ }^{17}$

For starters, Galileo and Bellarmine could each locate (e.g., point to, assert, etc.) a meta-standard (or many metastandards)_-viz., standards that specify what kinds of evidence are permitted in the context of the first-order dispute about moons. The problem is just that for any such metastandard (be it a rule or a normative principle ${ }^{18}$ ) one would be inclined to put forward, it seems that the other would be inclined to reject it. And so what (7) of the argument

\footnotetext{
$\overline{17 \text { Of course, }}$ certain kinds of problems for satisfying (7) will also make mischief for the relativist who relies on (6); and indeed, some of the specific problems I'll raise here for (7) do in fact raise problems for (6) - especially as 'availability' features in both premises. Accordingly, in developing problems for the relativist who wants to defend (7), I am not suggesting that (6) should be 'granted' or is otherwise unproblematic. On the contrary, I have in previous work on the 'No Neutrality, Therefore Relativism' argument, focused primarily on problems to do with (6). For a discussion of these problems, see in particular Carter (2016, Chap 4, 2018b).

18 We'll return later to the significance of this difference. For now, I'm using 'meta-standard' and 'metanorm' inclusively, so that a metanorm may be either a rule or a principle.
}

maintains is that neither can locate an appropriately neutral one. Both relativists such as Rorty and anti-relativists such as Siegel (2004, p. 751) and Boghossian (2006, pp. 61-62) are thinking of 'appropriate neutrality' in terms of something like 'non-question-beggingness' within a dialectical context, as follows:

\section{Appropriate neutrality (i.e., non-question-begging- ness): A metanorm, $M$, is appropriately neutral (i.e., non-questions-begging) between two systems $\mathrm{S} 1$ and $\mathrm{S} 2$ (in context D) iff either $\mathrm{M}$ is basic (primitive) or self-justifying in S1 and S2, or in cases where it is neither in either system, it can, in either system, be derived entirely from other principles of that system. ${ }^{19}$}

If we read premise (7) with the above gloss of 'appropriately neutral' (as it features in the premise), the idea would be: in the context of their dispute about moons, Galileo and Bellarmine can't locate a metanorm that is either primitive or self-justifying in both systems or derivable entirely from other principles of both systems.

The problem is, though, that there obviously are some metanorms that have this property and which are available (in any plausible sense of 'available') to both parties. Take, for example, a tautologous meta-norm Infer $X$ from $X$ (or an associated epistemic principle according to which inferences that follow the pattern 'Infer $\mathrm{X}$ from $\mathrm{X}$ ' are permissible). Plausibly the metanorm Infer $X$ from $X$ would be regarded as primitive in both systems. And the same goes for modus ponens, the law of the excluded middle and other such 'super-thin' metanorms. But, given that these kinds of super-thin metanorms are clearly available to both interlocutors, Galileo and Bellarmine, to (non-question-beggingly) appeal to in the context of their dispute, premise (7) - given the traditional 'appropriate neutrality' gloss of what it is that these interlocutors are said to be unable to locate-is manifestly false.

What this suggests is that the 'No Neutrality, Therefore Relativism' template argument attributed to the relativist needs a more charitable reconstruction than it's usually given (both by proponents and critics). In particular, what's needed is a more plausible version of (7). ${ }^{20}$ Making (7) more plausible requires (in short) adding to the description of what it is that Galileo and Bellarmine can't find. It has to be more than merely a metanorm that is appropriately neutral in the sense discussed.

What should such a description involve? Consider that while neither Bellarmine nor Galileo is in a position to

\footnotetext{
19 Thanks to the guest editors for suggesting this way of capturing the idea.

20 And then we'd need to amend (6) so that, with an amended version of (7), (8) would follow.
} 
object to each other relying on super-thin metanorms, such meta-norms are plausibly not going to be appropriately discriminatory (i.e., capable of assisting the interlocutors to move toward one rather than the other position) in the context of their dispute and this precisely because of their neutrality. Unsurprisingly, there is another side to this coin: a meta-norm that does very well in the discriminatory role (viz., by favouring one much more than the other) will plausibly fail to be appropriately neutral.

Putting these points together, a meta-standard can plausibly play the kind of role that it would need to play in order to facilitate bringing interlocutors locked into an otherwise irreconcilable position to a rational resolution, only if it is not merely suitably neutral, but moreover, it must also be non-inert (i.e., suitably discriminatory). Call a metanorm that is (i) suitably neutral and (ii) suitably non-inert Archimedean.

Archimedean metanorm: $M$ is an Archimedean metanorm in dialectical context $D$ if and only if $M$ is (i) appropriately neutral with respect to epistemic standards $S_{1}$ and $S_{2}$ in dialectical context $D$; and (ii) non-inert in dialectical context $\mathrm{D}$.

Galileo and Bellarmine could easily find appropriately neutral and (utterly) inert metanorms in the context of their dispute. But-and I think this better captures Rorty's point - they would have plausibly had more difficulty finding any appropriately neutral and non-inert metanorms-viz., metanorms the appeal by either to which would be (in some suitably specified way) capable of assisting the interlocutors to move rationally toward one rather than the other position-viz., an end to which Infer $X$ from $X$ (neutral as it may be) would be useless.

This all seems, at least initially, like good news for the relativist for the following reason: A point that had eluded previous attempts to construct a viable 'No Neutrality, Therefore Relativism' argument can be controlled for by simply amending (7) in the argument so that it claims that no Archimedean metanorm is available (as opposed to the claim that merely no appropriately neutral metanorm is available).

$7^{*}$. In the context of the dispute between Galileo and Bellarmine, no Archimedean meta-norm is available. ${ }^{21}$

Unlike (7), $\left(7^{*}\right)$ is not manifestly false. However, even with the improved $\left(7^{*}\right)$ in play rather than (7), the underlying concerns driving the elusiveness question remain.

\footnotetext{
21 This amendment will also require a tweak to (6) so that (8) follows-viz., 6*. There can be a non-relative resolution of the dispute concerning the existence of the moons, only if there is available an Archimedean metanorm.
}

\section{Three Problems}

Thus far, we've made some progress in specifying what it is that Galileo and Bellarmine are said to be unable to locate in their dialectical context (though we've yet to engage with the matter of what it would be for an Archimedean metanorm to be 'unavailable'). But, as I now want to suggest, even the improved formulation-one framed in terms of Archimedean metanorms-leaves much more to be answered, and this is only magnified when we attempt to unpack the notion of 'unavailability' in a plausible way.

In this section, the aim will be to show that attempts to sharpen the relativist's argument by addressing the elusiveness question reveal a trio of new problems:

(i) a definitional problem;

(ii) a methodological problem; and

(iii) an epistemic problem.

Let's consider each in turn.

\subsection{The Definitional Problem}

What counts as 'non-inert' in the context at issue-i.e., in characterising the kind of Archimedean metanorm that the relativist wants to say is not available in cases like Galileo versus Bellarmine? ${ }^{22}$

As we've already noted, a suitably non-inert norm must at least not be $s o$ neutral, in the context of the dispute, that appealing to it could not assist the project of rational adjudication. But what would a positive characterisation look like?

Here is a first pass.

Non-inertness: In a context, $D$, where $(D i) A$ and $B$ disagree about the truth of a proposition $p$ (e.g., heliocentrism), and (Dii) $A$ and $B$ disagree about which epistemic standards, $S_{1}$ or $S_{2}$ (e.g., Scripture, Science, etc.), are relevant to determining the truth of proposition $p$, a metastandard $M$ is appropriately non-inert if and only if either $S_{1}$ or $S_{2}$ is made more probable by $M$.

Of course, from each perspective, each interlocutor might believe a given metanorm makes their own position more probable than the other. Moreover, each might be working with different, subjective and incompatible construals of probability (e.g., $p$ is more probable than $q$ if and only if the Poison Oracle says that $p$ is more probable than $q$ ). Such considerations count in favour of an objective notion of

\footnotetext{
${ }^{22}$ Note that the kind of non-inertness of interest here is not noninertness simpliciter, but non-inertness in the context of a disagreement where (i) and (ii) are present.
} 
probability as the relevant one for the purposes of specifying non-inertness.

But then there are two problems. Firstly, many of the kinds of metastandards that are appropriately neutral will be, or be framed largely in terms of, logical truths, and logical truths (setting aside caveats) are necessarily true. ${ }^{23}$ But such truths won't then be useful qua objective probability raisers for any one metastandard over another. Secondly, and perhaps more problematically, probability raising itself may not be recognised within some epistemic systems [e.g., that of the characterization of the Azande given by EvansPritchard $\left.(1937)^{24}\right]$ as having evidential import. ${ }^{25}$ This matters because a definition of an Archimedean metanorm should be statable at a level of substantive generality; if it is not, then the relativist's appeal to it will appear ad hoc.

Let's consider now a different approach to non-inertness:

Non-inertness*: In a context, $D$, where $(D \mathrm{i}) A$ and $B$ disagree about the truth of a proposition $p$ (e.g., heliocentrism), and (Dii) $A$ and $B$ disagree about which epistemic standards, $S_{1}$ or $S_{2}$ (e.g., Scripture, Science, etc.), are relevant to determining the truth of proposition $p$, a metastandard $M$ is appropriately non-inert if and only if $S_{1}$ and $S_{2}$ differ in the extent to which, for $A$ and $B$, they depend on the truth of $M$.

Let ' $E$ ' be whatever evidence $A$ might adduce in favour of $S_{1}$ and let ' $E^{*}$ ' be whatever evidence $B$ might adduce for $S_{2}$. Now suppose that, for some meta-standard $M$, if $A$ doubted $M, A$ could rationally believe $S_{1}$ on the basis of $E$; but, if $B$ doubted $M, B$ couldn't rationally believe $S_{2}$ on the basis of $E^{*}$. In such a case, $S_{1}$ and $S_{2}$ differ in the extent to which (for $A$ and $B$, respectively) they depend on the truth of $M .{ }^{26}$ Problematically, though, this difference in dependence would have as a consequence that at least one of the interlocutors (in the above example, $B$ ) would be appealing to $M$ in a way that the other party may legitimately object to as epistemically circular. Such a difference in dependence may accordingly potentially hinder rather than help the prospects of rational adjudication between interlocutors.

Perhaps we might try then a different tack, one that seems to circumvent the worries raised for both Non-inertness and Non-inertness*:

Non-inertness**: In a context, $D$, where $(D \mathrm{i}) A$ and $B$ disagree about the truth of a proposition $p$ (e.g., heli-

\footnotetext{
${ }^{23}$ See Gomez-Torrente $(2017, \S 1.1)$ for helpful discussion.

${ }^{24}$ I make no claims here as to the accuracy of Evans-Pritchard's characterisation of the Azande.

25 It's interesting to note though, as Hacking (2006) has pointed out, there was no probability theory in the West before Pascal.

${ }^{26}$ In the language of Pryor (2004, p. 359) may say that Type 4 dependence is exhibited in one case, but not in the other.
}

ocentrism), and (Dii) $A$ and $B$ disagree about which epistemic standards, $S_{1}$ or $S_{2}$ (e.g., Scripture, Science, etc.), are relevant to determining the truth of proposition $p$, a metastandard $M$ is appropriately non-inert if and only if $M$ plays the following functional role: if $A$ and $B$ were to correctly identify $M$ as common ground between them, $A$ and $B$ couldn't easily fail at (or: would easily enough succeed at) reaching an agreement vis-à-vis $p$ (one way or another) if they try.

Non-inertness ${ }^{* *}$ is a modal construal of non-inertness, one that, in effect, maintains that $M$ is non-inert just in case the appeal to it is in a certain respect safely conducive to a resolution of the target proposition. ${ }^{27}$ While this idea might seem initially promising, there is a problem: whether or not $A$ and $B$ would, or would not, easily reach an agreement if they try is almost always a matter of non-epistemic factors, such as tiredness, distractions, etc. But these kinds of facts are plausibly irrelevant to whether epistemic relativism is true; and accordingly, if the non-inertness feature of Archimedean metanorms is unpacked along the lines of Non-inertness ${ }^{* *}$, then it becomes hard to see why it should matter for the truth of epistemic relativism whether an Archimedean metanorm is available or not. (Though this is a problem we'll return to.)

In sum, then, if, in the context of the dispute between Galileo and Bellarmine, no Archimedean meta-norm is available (as the improved version of the No Neutrality, Therefore Relativism argument would have it), then what's not available is a meta-norm that's not just appropriately neutral but also in some suitably specified sense non-inert. However, there is no immediately obvious way to positively characterise non-inertness (as this is a feature of an Archimedean metanorm) that will be of use to the relativist.

\subsection{The Eureka Problem}

Suppose for the sake of argument that the matter of how the relativist might suitably articulate 'non-inertness' (in giving a positive characterisation of an Archimedean metanorm) could be overcome. Even so, a methodological problem remains.

Question: What exactly is involved in the activity of 'finding' or 'locating' an Archimedean metanorm when that activity is successful? That is, when do interlocutors actually count as finding the thing that (according to the relativist), if they didn't (or couldn't) find it in the right kind of way in the context of their dispute, then this would be motivation for relativism? Call this methodological question the 'eureka question'.

\footnotetext{
$\overline{27}$ See Rabinowitz (2011) an overview of safety as a modal condition.
} 
One simple answer to the eureka question proceeds as follows: what's involved is just the recognition, by both parties to the dispute, of an Archimedean metanorm, that it is common ground between them. In a bit more detail:

Locating Common Belief View (LCBV): There is some Archimedean metanorm, $M$, such that $A$ and $B$ both believe that $M$ is true; and through dialogue, $A$ and $B$ come to believe that $A$ and $B$ both believe that $M$ is true. (E.g., Bellarmine and Galileo both believe some basic principle and then recognise that they both believe it.)

LCBV offers what is probably the most natural answer to the eureka question. If LCBV is correct, then the way to read $(7 *)$ in the revamped 'No Neutrality, Therefore Relativism Argument' is as follows: in the context of the dispute between Galileo and Bellarmine, no Archimedean metanorm is available insofar as it's not possible (in some suitably specified sense of possibility) for both parties to 'find' an Archimedean metanorm, $M$, in the sense specified in LCBV_-viz., that it's not possible for both parties to come to believe that both believe $M$.

There is a hitch with LCBV. Norms (meta- or otherwise), strictly speaking, are not believed: they are rules that are followed or not followed. ${ }^{28}$ For example: if the Poison Oracle indicates that $X$, believe $X$; if it visually seems to you that $p$, then believe $p$, etc. This much suggests that LCBV should be reframed either as a view about (something like) (i) mutual recognition of shared norm compliance (as opposed to mutual recognition of common norm belief) where the norms themselves are not truth-apt and so not believed ${ }^{29}$; or, as a view about (something like) (ii) mutual recognition of shared belief, with respect to some (truth-apt) epistemic principle, that that epistemic principle is true, where 'epistemic principles' may be defined, following Boghossian (2006), as 'general normative [sic. truth-apt] propositions' which specify conditions under which a particular type of belief is justified (e.g., Beliefs issued by the Bible are justified, Beliefs supported by our best scientific theories are justified.)

A problem with going the first route is that it reduces the 'finding' of an Archimedean metanorm to reflecting on

\footnotetext{
28 'Following a rule', in the sense of following an epistemic norm, needn't involve any kind of active reflection on the rule in question. For example, one follows the knowledge norm of assertion just in case one knows what one asserts, and regardless of whether one is trying to follow this norm.

${ }^{29}$ Such a principle might be stated as follows: There is some Archimedean metanorm, $M$, such that $A$ and $B$ both comply with $M$; and through dialogue, $A$ and $B$ come to believe that ' $A$ and $B$ both comply with $M^{\prime}$ is true. (E.g., Bellarmine and Galileo both comply with basic principle and then recognise that they both comply with it).
}

past patterns of norm compliance. This is of no help to the relativist, as it would mean unpacking:

7*. In the context of the dispute between Galileo and Bellarmine, no Archimedean meta-norm is available.

as

(!) $7^{*}$. In the context of the dispute between Galileo and Bellarmine, no Archimedean meta-norm is such that both parties mutually believe they have complied with it.

But whereas the relevance of $7 *$ to the conclusion of relativism is not bizarre, the relevance of $(!) 7^{*}$ would be. (For, after all, both parties may be well positioned to comply with a given Archimedean metanorm in the future even if they have not done so in the past.) What this suggests is that the relativist is best served by opting for an 'epistemic principle' gloss of LCBV to the effect that 'finding' an Archimedean metanorm-cum-epistemic-principle would involve Bellarmine and Galileo both (i) believing of some basic epistemic principle that it's true; and then (ii) recognising that they both believe it.

But now a different kind of objection waits in the wings. If the 'epistemic principle' gloss of LCBV is right, then the mere fact of two epistemic expressivists locked in a dispute would be evidence for epistemic relativism, simply because, qua non-cognitivists, they lack the requisite beliefs! And this would be so even if those epistemic expressivists were capable of reaching an attitudinal agreement, e.g., if they both shared the same pro-attitude.

Even setting these points aside, there may be a more difficult problem for accounting for what interlocutors would actually have to do to find the thing that (according to the relativist), if they didn't (or couldn't) find in the right kind of way in the context of their dispute, this would be motivation for relativism.

For reference, we may call this further problem the levels of doxastic assent problem. Suppose for illustrative purposes that something like LCBV is right. Now, suppose that both parties to the dispute in question believe that some Archimedean metanorm is common ground between them, but suppose further that these interlocutors fail to appreciate of the Archimedean metanorm which they both accept and accept that the other accepts that it is an Archimedean metanorm in the context of their dispute. Locating an appropriately neutral and non-inert metanorm in this fashion would not be much more helpful in the service of actually bringing both interlocutors to a rational resolution than were they to have merely located a super-thin (i.e., appropriately neutral) but entirely inert metanorm which they appreciate is appropriately neutral.

What this indicates is that (something like) LCBV answers the methodological 'eureka' question only if we 
added a 'further belief' requirement to (whatever version we prefer of) LCBV to the effect that: $A$ and $B$ must accept $M$, realise that both $A$ and $B$ accept $M$, and believe of $M$ that $M$ is Archimedean (i.e., suitably neutral and non-inert) in the context of their dispute.

This looks better. But things are hardly in the clear. Now just imagine that both interlocutors satisfy the above 'further belief requirement', and yet, have no idea how to use the Archimedean metanorm (which each accepts, accepts the other accepts, and believes to be Archimedean in the context of their dispute) to resolve their first-order disagreement.

Now it seems yet a further belief requirement is needed to the effect that, for some $w, w$ is the way to use $M$ to reach a resolution. The doxastic ascent problem is now in full swing. For as Ryle (1945) has pointed out-following Carroll (1895) - it's always possible for one to know of some way that that's the way to do something without being able to do the thing in question. In Ryle's example, a student is given fact after fact about how to draw an inference, and yet it remains conceivable that despite believing (and perhaps even knowing) this (large) set of facts about how to draw the inference, the pupil remains unable to do so.

Ryle's own assessment of the situation is that the student, in the circumstance described, failed to know how to draw an inference despite the stock of propositional knowledge the student had, and correlatively, that possessing relevant know-how required ability and not just propositional knowledge. We needn't take a stand on what know-how involves to see already what might look like a way to stop the increasing levels of doxastic ascent. The idea is to simply add an ability condition. The relevant requirement then would be that $A$ and $B$ must (i) accept $M$, (ii) realise that both $A$ and $B$ accept $M$, (iii) believe of $M$ that $M$ is Archimedean (i.e., suitably neutral and non-inert) in the context of their dispute, (iv) believe (correctly) for some $w, w$ is the way to use $M$ to reach a resolution, and (v) possess jointly the ability to resolve their dispute with reference to $M$.

Unfortunately for the relativist, even at this stage, another level of doxastic ascent threatens. For, regarding condition (v), just consider that $A$ and $B$ might in fact jointly possess the ability to resolve their dispute with reference to $M$ but have no idea that they have the ability to do this. And indeed such ignorance is actually common. ${ }^{30}$ Failure to recognise such abilities (by failing to having certain further beliefs) will presumably lead interlocutors to quit too quickly-it might prevent us from intentionally trying to do the things that the abilities are abilities to do. But now yet a further belief is needed to the effect that the interlocutors (correctly)

\footnotetext{
30 This is so even amongst experts who systematically underestimate their levels of ability (e.g., Kruger and Dunning 1999).
}

believe that they have such abilities, not merely that they have them.

Let's set aside whether this last move closes the needtoward the end of answering the eureka question-for further levels of doxastic ascent. There is a final related problem worth considering, one that takes (given certain empirical premises) the form of a dilemma.

Consider that any relativist who embraces a premise like $7 *$ in an argument for epistemic relativism is committed to the more general thesis that it matters for relativism whether $A$ and $B$ can, in the context of a given dispute, locate an appropriately neutral and non-inert (i.e., Archimedean) metanorm. Presumably, if it matters for relativism whether $A$ and $B$ can locate an appropriately neutral and appropriately non-inert metanorm, it matters for relativism whether $A, B$ and $C$ can (in the context of a dispute between $A, B$ and $C)$ locate such an appropriately neutral and appropriately non-inert metanorm.

This suggests the relativist will be plausibly committed to the following iteration principle:

Iteration principle: For any finite number of interlocutors $I$ and any deliberative context $D$, if it matters for relativism whether the interlocutors $I$ can locate in $D$ an appropriately neutral and appropriately non-inert (i.e., Archimedean) metanorm, it matters for relativism whether $I+n$, for any interlocutor $n$ who is a member of $D$, can locate such an appropriately neutral and appropriately non-inert (i.e., Archimedean) metanorm.

For any relativist who rejects the iteration principle, there would need to be a (very) good reason why Galileo and Bellarmine's dispute could serve as a basis for motivating relativism, given what was not available to them in the context of their dispute, even while a hypothetical dispute between Galileo and his likeminded assistant and Bellarmine and his likeminded assistant, would not.

This doesn't look promising, and so the relativist should really embrace the iteration principle. However, in doing so, the relativist runs in to an empirical problem that gives way to a dilemma. It is well documented that large groups, when deliberating about a given matter (and where the members of the group have non-negligible initial leanings) tend to move toward more extreme positions than those initially held. For example, in a famous study by Moscovici and Zavalloni (1969), it was shown that groups (post-deliberation) tend to hold stronger political views than those initially held by their individual members. Likewise, group racial attitudes become stronger after already prejudiced members discuss racial issues (Myers and Bishop 1970). ${ }^{31}$

\footnotetext{
${ }^{31}$ For a more detailed discussion, see Broncano-Berrocal and Carter
} (2018). 
This is the phenomenon of group polarisation. Crucially, in cases of group polarisation, the very fact of deliberating in such contexts (for various reasons) leads to polarisation. Which psychological factors cause individuals to move to more extreme positions in group contexts is debated. For example, according to self-categorization theory (Turner 1982; Turner et al. 1987) confrontation in a group deliberative setting enhances group membership and self-identity in a way that (i) minimizes intragroup differences and (ii) maximizes intergroup differences. The crux of the idea is that groups polarise because their members try to preserve their distinctiveness from other groups. Relatedly, social comparison theory (e.g., Festinger 1954) maintains that the underlying cause of group polarisation is a need for social approval. ${ }^{32}$ Neither of these underlying causes supports an epistemic reason for polarising.

We're now in a position to state a kind of trilemma for the would-be 'No Neutrality, Therefore Relativism' relativist. It looks as though she has three options, each with an associated cost. The relativist can either accept or deny the iteration principle. Denying it is unacceptably arbitrary. If she accepts it, then she can either (i) allow that non-epistemic considerations (e.g., biases of the sort that lead to polarisation in groups) which lead to a lack of agreement are relevant to the truth of relativism, or she can deny this and maintain that only epistemic considerations which lead to a lack of agreement are relevant to the truth of relativism. The former route is unprincipled; the latter route at best leaves the relativist in need of further argument.

\subsection{The Epistemic Problem}

I've suggested that attempts to sharpen the relativist's 'No Neutrality, Therefore Relativism' argument by addressing the elusiveness question reveal a trio of new problems: (i) a definitional problem, (ii) a methodological problem and (iii) an epistemic problem. The definitional and methodological problems have been discussed. Let's turn now to the epistemic problem.

Suppose for the sake of argument that the doxastic ascent problem can be dealt with by the relativist, along with the definitional and other problems. Let's now suppose that the following claim, congenial to the relativist, is true:

Unlocatability (datum): Sometimes, it is not possible for interlocutors to locate an Archimedean metanorm in the context of their dispute in an epistemically satisfactory way.

The qualification 'in an epistemically satisfactory way' is meant to control for the following: it would

32 See Broncano-Berrocal and Carter (2017) for an overview of these underlying causes. presumably always be possible to stumble upon an Archimedean metanorm accidentally, e.g., just by guessing, for any Archimedean metanorm that could be located nonaccidentally. (On such an assumption, for instance, each of the requirements specified by the doxastic ascent problem would itself be a condition satisfied by, say, guessing). It would likewise be possible to stumble upon an Archimedean metanorm through the use of reasoning processes that are prohibited by the epistemic principles that one already accepts. In a case like Bellarmine/Galileo, the relativist presumably wants to maintain that no Archimedean metanorm is available in a way that (in some sense) complies with the epistemic principles each already accepts.

Thus, the relevant datum the relativist is pointing to in a case like Bellarmine/Galileo, and which is taken to be relativism-relevant, should not be read as the (unqualified) claim that no Archimedean metanorm can be found (by any way, including ways that are prohibited by principles each accepts, respectively) but rather that no Archimedean metanorm may be found in a way that is epistemically satisfactory, at least, by the lights of each interlocutor's respective principles.

Now, if we are assuming, ex hypothesi, that this datum is correct, let's ask, what would best explain it? If the 'No Neutrality, Therefore Relativism' line for epistemic relativism is correct, then the relativist had better have a better explanation for this datum than a competing non-relativist explanation.

Consider now, the following proposal which we may call epistemicism:

Epistemicism: In some cases, the correct set of epistemic principles (including the most general principles, such as those that might play the role of ' $M$ ') are unable to be known/justifiedly believed by interlocutors in light of the epistemic principles they already accept.

An epistemicist explanation of the unlocatability datum predicts that in some contexts, antecedently embraced epistemic principles (e.g., Bellarmine's allegiance to Scripture) might foreclose the possibility of embracing a given Archimedean metanorm (or, for that matter, any correct epistemic principle) in an epistemically satisfactory way. Accordingly, on this way of thinking, some Archimedean metanorms will be unknowable (or: unable to be held in an epistemically satisfactory way) but in a manner that is compatible with objectivism, and more generally, with metaepistemological realist views of the epistemic status of epistemic principles (e.g., Boghossian 2006; Carter 2016, Chap. 1).

The relativist's explanation of the unlocatability datum says that lack of an epistemically satisfactory location of an Archimedean metanorm in actual historical disagreements is evidence for relativism. But why prefer the latter to the former explanation?

This question at the heart of the epistemic problem connects closely with what was described initially as the relevance 
question-viz., why should it matter (for relativism) whether interlocutors could (or could not) locate such a thing, in the context of their dispute? Why should the matter of whether epistemic relativism is true turn on these kinds of facts?

The burden of proof here remains with the relativist, at least, if the relativist purports to offer a better explanation of allegedly irresolvable disagreements than objectivistfriendly explanations of such disagreements.

One specific objectivist-friendly philosophical position $v i s-\grave{a}-v i s$ irresolvable disagreements is the one offered by the Pyrrhonian sceptic, outlined at the beginning of the paper. As Hales (2014, p. 81) has suggested-in a recent paper defending a version of the 'No Neutrality, Therefore Relativism' argument- the view advanced by Pyrrhonian scepticism amounts to 'throwing in the towel', a response to sceptical views that is not uncommon. ${ }^{33}$

In previous work (e.g., Carter 2016, Chaps. 3-4, 2018a, b) I've offered various reasons for thinking that, if the choice were between relativism and Pyrrhonian scepticism, there are good reasons to throw in with the Pyrrhonian sceptic rather than with the relativist.

I won't rehearse these here. Rather, I want to close by pointing out that the meta-epistemological objectivist retains a solid position relative to the relativist even if we should (as I think we should not) throw in with the relativist rather than the Pyrrhonian. In order to see why, it's important to draw a distinction between (a) wholesale Pyrrhonian scepticism; and (b) a Pyrrhonian-style response to irresolvable disagreement. The most well-noted philosophical costs associated with (a) do not apply to (b). The strength of any form of scepticism is a function of (at least) its scope. The scope of traditional Pyrrhonian scepticism, as a philosophical position, is substantial, ${ }^{34}$ and the philosophical motivations for such a view outstrip whatever motivations are afforded by arguments from disagreement. The scope, and thus the strength, of (b) may in fact not be very substantial at all; and this means the correlative philosophical concession to the sceptic may accordingly not be very substantial—viz., just those propositions that are the loci of genuinely irresolvable disagreements. Such disagreements may in practice be rare. At any rate, should the relativist wish to show otherwise, she'd need to first be able to identify in a principled way just

\footnotetext{
33 Indeed, with very few exceptions (e.g., Lehrer 1971; Stroud 1984; Unger 1971) most epistemologists, even those who take sceptical arguments seriously (either Cartesian closure-based arguments or Pyrrhonian-style arguments) are not inclined to actually accept the sceptic's conclusion. Accordingly, as Pritchard (2015) notes, it is commonplace to view sceptical arguments as paradoxes-viz., intuitive premises that seem to entail a conclusion that is itself a problematic one to accept.

34 See Frede (1998) an excellent collection of essays that engage with the scope of Pyrrhonian scepticism.
}

what the markers of such disagreements are. And-if the definitional and methodological problems are anything to go by—doing this may be easier said than done. ${ }^{35}$

Open Access This article is distributed under the terms of the Creative Commons Attribution 4.0 International License (http://creativeco mmons.org/licenses/by/4.0/), which permits unrestricted use, distribution, and reproduction in any medium, provided you give appropriate credit to the original author(s) and the source, provide a link to the Creative Commons license, and indicate if changes were made.

\section{References}

Baghramian M, Carter JA (2015) Relativism. In: Zalta EN (ed) The stanford encyclopedia of philosophy (Summer 2017 Edition)

Barnes J (2007) The toils of scepticism. CUP, Cambridge

Boghossian P (2006) Fear of knowledge: against relativism and constructivism. OUP, Oxford

Broncano-Berrocal F, Carter JA (2017) Epistemic luck. In: Routledge Encyclopedia of Philosophy

Broncano-Berrocal F, Carter JA (2018) Group polarization as a collective epistemic vice. Unpublished manuscript

Campolo C (2007) Commentary on v. memedi: resolving deep disagreement. In: Hansen HV et al (eds) Dissensus and the search for common ground. OSSA, Windsor

Carroll L (1895) What the tortoise said to achilles. Mind 4:278-280

Carter JA (2016) Metaepistemology and relativism. Palgrave Macmillan, Basingstoke

Carter JA (2018b) Epistemic relativism and the naturalistic fallacy. In: Sinclair N (ed) The naturalistic fallacy. CUP, Cambridge

Carter JA (2018a) Epistemic disagreement, diversity and relativism. In: Graham P et al. (eds.) Routledge handbook of social epistemology

Cuneo T (2007) The normative web: An argument for moral realism. Oxford University Press

Elga A (2007) Reflection and disagreement. Noûs 41:478-502

Evans-Pritchard EE (1937) Witchcraft, oracles, and magic among the azande. Clarendon, Oxford

Feldman R (2007) Reasonable religious disagreements. In: Anthony, L (ed) Philosophers without gods: meditations on atheism and the secular. OUP, Oxford, pp 194-214

Festinger L (1954) A theory of social comparison processes. Hum Relat 7:117-140

Fogelin RJ (1985) The logic of deep disagreements. Informal Log $7: 1-8$

Frede M (1998) The sceptic's beliefs. In: Burnyeat M, Frede M (eds) The original sceptics: a controversy. Hackett, Indianapolis, pp $1-24$

Gomez-Torrente M (2017) Logical truth. In: Zalta EN (ed) The stanford encyclopedia of philosophy (Summer 2017 Edition)

Hacking I (2006) The emergence of probability: a philosophical study of early ideas about probability, induction and statistical inference. CUP, Cambridge

Hales SD (2014) Motivations for relativism as a solution to disagreements. Philosophy 89:63-82

\footnotetext{
35 Thanks to Patrick Bondy, David Godden and two anonymous referees for helpful feedback. Thanks also to audiences at York University, Edinburgh University, the University of Vienna and University College Dublin. A special thanks to Maria Baghramian for her encouragement and support.
} 
Kölbel M (2004) Faultless disagreement. In: Proceedings of the aristotelian society (Hardback), Wiley online library, pp 53-73

Kruger J, Dunning D (1999) Unskilled and unaware of it: how difficulties in recognizing one's own incompetence lead to inflated self-assessments. J Personal Soc Psychol 77:1121

Lammenranta M (2008) The pyrrhonian problematic. In: Greco J (ed) The oxford handbook of skepticism. OUP, Oxford, pp 9-33

Lehrer K (1971) Why Not Scepticism? Philos Forum 2(3):283

MacFarlane J (2007) Relativism and disagreement. Philos Stud 132:17-31

MacFarlane J (2008) Boghossian, bellarmine, and bayes. Philos Stud 141:391-398

MacFarlane J (2014) Assessment sensitivity: Relative truth and its applications. OUP Oxford, Chicago

Machuca DE (2011) The pyrrhonian argument from possible disagreement. Archiv für Geschichte der Philosophie 93(2):148-161

Moscovici S, Zavalloni M (1969) The group as a polarizer of attitudes. J Personal Soc Psychol 12:125

Myers DG, Bishop GD (1970) Discussion effects on racial attitudes. Science 169:778-779

Pritchard D (2015) Epistemic angst: radical skepticism and the groundlessness of our believing. Princeton University Press, Princeton

Pryor J (2004) What's wrong with moore's argument? Philos Issues $14: 349-378$
Rabinowitz D (2011) The safety condition for knowledge. Internet encyclopedia of philosophy. https://www.iep.utm.edu/safety-c/

Rorty R (1979) Philosophy and the mirror of nature. Princeton University Press, Princeton

Ryle G (1945) Knowing how and knowing that: the presidential address. In: Proceedings of the Aristotelian Society, pp 1-16

Siegel H (2004) Relativism. In: Sintonen M, Wolenski J, Niiniluoto I (eds) Handbook of epistemology. Kluwer Academic, Dordrecht, pp 747-780

Siegel H (2011) Epistemological relativism: arguments pro and con. In: Hales SD (ed) A companion to relativism. Wiley, Chichester, pp 199-218

Siegel H (2013) Argumentation and the epistemology of deep disagreement. Cogency 5:135-170

Stroud B (1984) The significance of philosophical scepticism. OUP, Oxford

Turner JC (1982) Towards a cognitive redefinition of the social group. In: Tajfel H (ed) Social identity and intergroup relations. Cambridge University Press, Cambridge, pp 15-40

Turner JC, Hogg MA, Oakes PJ, Reicher SD, Wetherell MS (1987) Rediscovering the social group: a self-categorization theory. Basil Blackwell, Cambridge

Unger P (1971) A defense of skepticism. Philos Rev 80:198-219 